\title{
Tool to address green roof widespread implementation effect in flood characteristics for water management planning
}

\author{
R. Tassi, F. Lorenzini, and D. G. Allasia \\ Federal University of Santa Maria, Santa Maria, Brazil \\ Correspondence to: R. Tassi (rutineia@gmail.com)
}

Received: 11 March 2015 - Accepted: 11 March 2015 - Published: 11 June 2015

\begin{abstract}
In the last decades, new approaches were adopted to manage stormwater as close to its source as possible through technologies and devices that preserve and recreate natural landscape features. Green Roofs (GR) are examples of these devices that are also incentivized by city's stormwater management plans. Several studies show that GR decreases on-site runoff from impervious surfaces, however, the analysis of the effect of widespread implementation of GR in the flood characteristics at the urban basin scale in subtropical areas are little discussed, mainly because of the absence of data. Thereby, this paper shows results related to the monitoring of an extensive modular GR under subtropical weather conditions, the development of a rainfall-runoff model based on the modified Curve Number (CN) and SCS Triangular Unit Hydrograph (TUH) methods and the analysis of large-scale impact of GR by modelling different basins. The model was calibrated against observed data and showed that GR absorbed almost all the smaller storms and reduced runoff even during the most intense rainfall. The overall $\mathrm{CN}$ was estimated in 83 (consistent with available literature) with the shape of hydrographs well reproduced. Large-scale modelling (in basins ranging from 0.03 ha to several square kilometers) showed that the widespread use of GRs reduced peak flows (volumes) around $57 \%(48 \%)$ at source and $38 \%$ (32\%) at the basin scale. Thus, this research validated a tool for the assessment of structural management measures (specifically GR) to address changes in flood characteristics in the city's water management planning. From the application of this model it was concluded that even if the efficiency of GR decreases as the basin scale increase they still provide a good option to cope with urbanization impact.
\end{abstract}

\section{Introduction}

The principles of the Low Impact Development (LID) indicate that the control of the added runoff by urbanization must be carried out as close as to its source as possible, in order to minimize or eliminate the effect of hydrological man-made changes to the environment (i.e. achieve no impact due to urbanization in hydrological conditions). Green roofs (GR) are example of techniques applied to achieve this goal, as GR's vegetation and its soil substrate controls the surface runoff, recovering the interception, water retention and evapotranspiration processes affected by land use changes (Yang et al., 2008).

Using this technique in large scale helps maintaining the ecological and hydrological functions in the basin, being characterized by the Water Environment Research Foundation as a sustainable practice to rainfall drainage (Clark et al., 2006).

Besides, several studies highlight other benefits in the use of GR, such as improving the quality of the environment, reducing heat island effect (Rosenzweig et al., 2006), sequestering pollutants (Yang et al., 2008) and increasing the biodiversity and habitat availability in urban areas (Kim, 2004). They also improve thermal (Vecchia, 2005; Beyer, 2007) and acoustic comfort (Renterghem and Botteldooren, 2009) and promote energy savings (Gibbs et al., 2006).

However, the analysis of the effect of widespread implementation of GR in the flood characteristics at the urban basin scale in subtropical areas are little discussed, mainly because of the absence of data. In this light, this paper 
shows results related to the monitoring of a Modular Extensive Green Roof (MEGR) under subtropical weather conditions, the development of a rainfall-runoff model based on the modified Curve Number (CN) and SCS Triangular Unit Hydrograph (TUH) methods and the analysis of large-scale impact of GR on the quantitative control of the runoff.

\section{Monitoring}

The data obtained from the behavior of the MEGR, as surface rainfall and runoff used for developing the hydrological model are the result of monitoring a GR with a total area of $6 \mathrm{~m}^{2}$, placed in the Federal University of Santa Maria (UFSM), Santa Maria - Brazil.

The GR is of extensive type (shallow and lighter than intensive green roofs with minimal maintenance requirements), comprised of an arrange of prefabricated modules of Ethylene-vinyl acetate (EVA) of $35 \times 70 \times 9 \mathrm{~cm}$ that holds substrate and vegetation over a plastic sealed container of 3 $\mathrm{cm}$ high, whose function is to retain part of the rainfall during drought periods (Fig. 1). The rainfall excess volume (runoff), which is not stored in the MEGR is drained by a pipe to a 500-L reservoir located under the monitored structure. The reservoir was emptied after each rainfall event, however during three events in weekends occurred overtopping.

The area was monitored between the months of November 2010 and April 2013. The plant species cultivated in the green roof were: Gazania rigens, Chlorophytum comosum, Asparagus-densiflorus "sprengeri”, Echeveria, Sedum dendroideum, Kalanchoe blossfeldiana, Coleus barbatus and Sedum album. The four latter species presented higher resistance to the climate in the subtropical area; therefore, they are more abundant in the vegetation coverage.

A pluviograph and a pluviometer installed on the top of the GR measured the rainfall. In turn, runoff was diverted to the reservoir that was monitored in a 2 min interval by means of a Differential Pressure Level meter allowing excess runoff measure. This procedure also allowed to identify eventual overtopping during the monitoring.

\section{A rainfall-runoff model for MEGR}

\subsection{Effective rainfall estimative}

Effective rainfall from the MEGR was used to estimate the Curve Number (CN) (NRCS, 1986) parameter for a selection of 48 monitored rainfall-runoff events. $\mathrm{CN}$ was selected among numerous methods because its simplicity and being widely used in Brazil.

However, the original $\mathrm{CN}$ method was modified eliminating initial abstractions (considered as $20 \%$ in the original method) following several authors (e.g. Park and Cameron, 2008; Nagase and Dunnett, 2012) due to the reduced capacity of surface interception and retention provided by the selected vegetation. In this way, in the modified equation the

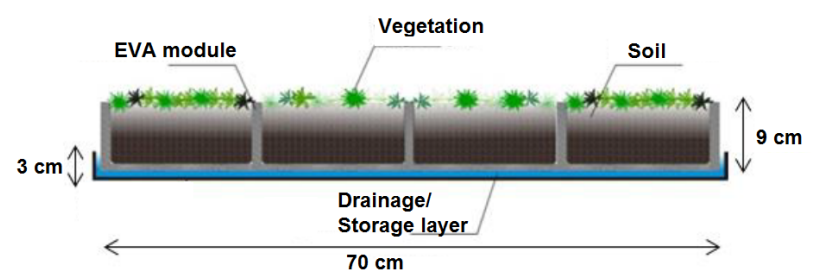

a) Side view

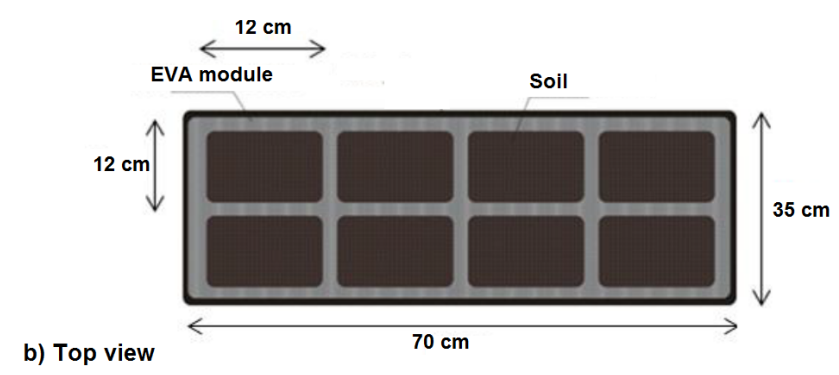

Figure 1. Modular green roof characteristics: side view (a) and top view (b).

soil storage value $(S)$ represents maximum soil water retention on GR herewith initial abstraction. This turns $S$ into the calibration objective (Eq. 1).

$S=\frac{P^{2}-P_{\mathrm{ef}} \cdot P}{P_{\mathrm{ef}}}$

where $P$ is the total volume of rainfall (in $\mathrm{mm}$ ), $P_{\mathrm{ef}}$ is the effective rainfall leaving the MEGR (in $\mathrm{mm}$ ) and stored in the reservoir during rainfall, and $S$ the maximum soil water retention (+ initial abstraction) in the MEGR (in mm).

After determining $S$ in Eq. (1), the next step was the calculation of the $\mathrm{CN}$ value for the green roof $\left(\mathrm{CN}_{\mathrm{GR}}\right)$ for each event through traditional SCS method equation $\mathrm{CN}_{\mathrm{GR}}=(25400 / S+254)$. The final $\mathrm{CN}_{\mathrm{GR}}$ value was obtained from the analysis of the mean, median, minimum, maximum, standard deviation and $95 \%$ confidence interval (CI) values for the 48 events.

\subsection{Runoff hydrograph estimative}

The runoff hydrograph was determined by means of a modified SCS Triangular Unit Hydrograph (TUH) (NRCS, 2007) to represent the MEGR's behavior (GR-TUH). The GR-TUH parameters (Table 2) were calibrated minimizing the error in the volume between observed and calculated hydrographs represented by the Nash-Sutcliffe coefficient in each event. The mean GR-TUH was selected as the best fit.

\section{Green roof widespread implementation analysis}

The analysis of the effect of GR in the runoff in different scales was accomplished by comparing peak flows and volumes in different points with drainages areas between 
Table 1. $\mathrm{CN}_{\mathrm{GR}}$ values estimated and statistics.

\begin{tabular}{lcccccc}
\hline Average & \multicolumn{5}{c}{ CN-GR } \\
\cline { 2 - 7 } $\begin{array}{l}\text { rainfall } \\
(\mathrm{mm})\end{array}$ & Mean & Median & $\begin{array}{c}\text { Standard } \\
\text { deviation }\end{array}$ & Minimum & Maximum & CI 95\% \\
\hline 33.8 & 83 & 85 & 15 & 27 & 100 & $78-87$ \\
\hline
\end{tabular}

Table 2. Parameters used for defining the TUH-SCS and the GRTUH.

\begin{tabular}{ll}
\hline $\begin{array}{l}\text { TUH-SCS (original } \\
\text { parameters) }\end{array}$ & $\begin{array}{l}\text { GR-TUH (calibrated } \\
\text { parameters) }\end{array}$ \\
\hline$t_{p}=0.6 \cdot t_{\mathrm{c}}$ & $t_{p}^{*}=1.2 \cdot t_{\mathrm{c}}$ \\
$T_{p}=D_{t} / 2+0.6 \cdot t_{\mathrm{c}}$ & $T_{p}^{*}=D_{t} / 2+1.2 \cdot t_{\mathrm{c}}$ \\
$t_{\mathrm{r}}=1.67 \cdot T_{p}$ & $t_{\mathrm{r}}^{*}=0.57 \cdot T_{p}^{*}$ \\
$Q_{\mathrm{p}}=(0.208 \cdot A) / T_{p}$ & $Q_{\mathrm{p}}^{*}=(0.3538 \cdot A) / T_{p}^{*}$ \\
\hline
\end{tabular}

where: $t_{p}$ and $t_{p}^{*}$ are the lag time, $t_{\mathrm{c}}$ the time of concentration, $T_{p}$ and $T_{P}^{*}$ are time of rise, $D_{t}$ rainfall duration, $t_{\mathrm{r}}$ and $t_{\mathrm{r}}^{*}$ are the recession time, $Q_{\mathrm{p}}$ and $Q_{\mathrm{p}}^{*}$ are the peak flow; $A$ is the GR drainage area. Units: $t_{p}, t_{\mathrm{p}}^{*}, t_{\mathrm{c}}, T_{p}, T_{p}^{*}, D_{t}, t_{\mathrm{r}}, t_{\mathrm{r}}^{*},(\mathrm{~h}) ; Q_{\mathrm{p}}$ $\left(\mathrm{m}^{3} \mathrm{~s}^{-1} / 1 \mathrm{~mm}\right) ; A\left(\mathrm{~km}^{2}\right)$.

0.03 and 30.68 ha at the Arroio Areia urban basin of Porto Alegre (Brazil). This basin has been extensively studied in several studies including the Porto Alegre's Urban Drainage Master Plan (Tassi, 2002; Tassi and Villanueva, 2004).

For practical reasons, the chaotic land use composed of several size lots was simplified, but the real basin occupation pattern was respected. Land use was represented by a total of 27600 lots of $300 \mathrm{~m}^{2}$, using a detailed representation of the basin's surfaces (roofs, sidewalks, lawns, public walks and streets), including the configuration of the real drainage systems resulting in $59 \%$ impervious area. The larger slope of $6 \%$ was found in the upstream areas being the lower near the basin outlet flat (slope of $0.04 \%$ ). This approach resulted in a synthetic basin whose physical characteristics are nearly identical to the real one and has been used by previous researchers (James et al., 1987; Goff and Gentry, 2006), because offers a controlled environment for analysis that allows the effects of specific variables to be pinpointed (Goff and Gentry, 2006).

The detailed modeling of the basin was fulfilled by a modification of the Schaake (1971) model (Tassi, 2002; Tassi and Villanueva, 2004). In this model, the effective rainfall process is accomplished by $\mathrm{CN}$ methodology and the runoff propagation over surfaces, pipes and channels is routed by the kinematic wave approach. The model used for MEGR rainfall-runoff process was that previously presented in Sect. 3 (CN-GR + GR-TUH) and coupled when necessary.

In order to assess the impact of the GRs on runoff in minor drainage system in several spatial scales, the simulation process was executed with and without MEGR (WMEGR) in the lots. After each simulation, the drainage system's discharges and volumes were analyzed in several positions in the basin allowing to quantify the GR efficiency in reducing these value at different scales, i.e. the relationship between the values with the MEGR and WMEGR. This process was repeated for hydrograph design and observed rainfall-runoff events.

\section{Results}

\subsection{Monitoring and development of rainfall-runoff model for MEGR}

In Table 1 are presented the statistics of the $\mathrm{CN}_{\mathrm{GR}}$ calibration from the selected 48 rainfall events. The average value of the $\mathrm{CN}_{\mathrm{GR}}$ was 83 , which is consistent with the available literature for extensive GR systems. For example, Carter and Rasmussen (2006) reported a $\mathrm{CN}_{G R}$ of 86 ; a similar value of 84 was reported by Getter et al. (2007); in turn, Miller et al. (2010) reported values varying from 75 to 85 that is really close to our 78-87 confidence interval.

Those values suggest a reduction from the original $\mathrm{CN}$ of 98 (roof) to a closer to lawns or parks situation according to $\mathrm{CN}$ tables (NRCS, 1986). In other terms, represents a mean reduction of $45 \%$ of runoff volume at each event or a retention of $17 \mathrm{~L} \mathrm{~m}^{-2}$ of GR indicating that the MEGR would be almost equivalent to the maintenance of a pervious surface. These results confirm that GR can be considered an excellent alternative to compensate the impact of urbanization in urban areas.

As previously mentioned, the runoff hydrograph was determined by means of a modified SCS Triangular Unit Hydrograph (TUH) (NRCS, 2007). For this a time of concentration equal to 5 min (mean observed value) and a discretization of 2 min (equal to monitoring interval) were used. The GR-TUH parameters calibration indicated a more flat hydrograph, with lower peak flow and larger base flow, but always maintaining a unit response $(1 \mathrm{~mm})$.

The mean volume error was $7 \%$ between observed and calibrated hydrograph with mean Nash-Sutcliffe coefficients equal to 0.9 , while using the original TUH the found value were respectively, $7 \%$ and 0.6 .

This result indicates that the TUH method is suited to represent the behavior of runoff in the MEGR, and that the procedure used as the parameter is correct, especially when facing difficulties in representing complex phenomena of 


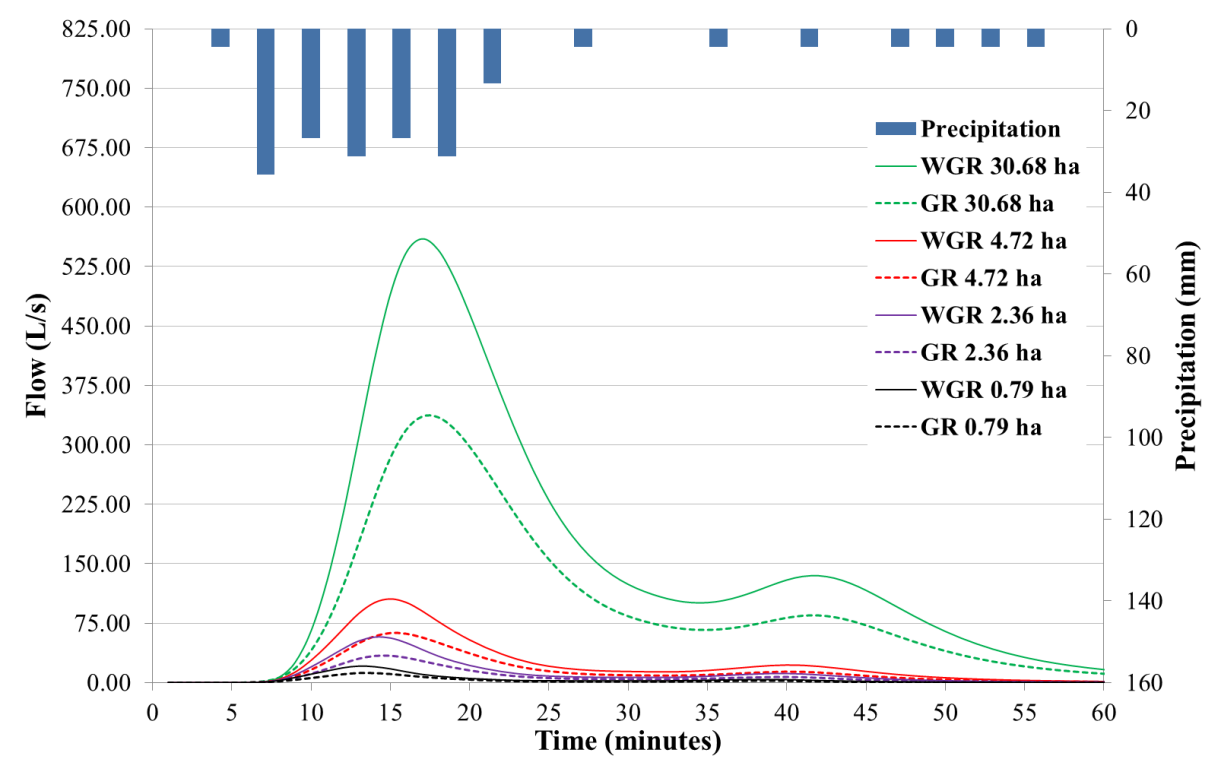

Figure 2. Hydrographs in drainage areas with $0.79,2.36,4.72$ and 30.68 ha for rainfall event 1 (WGR: without green roof; GR: with green roof).

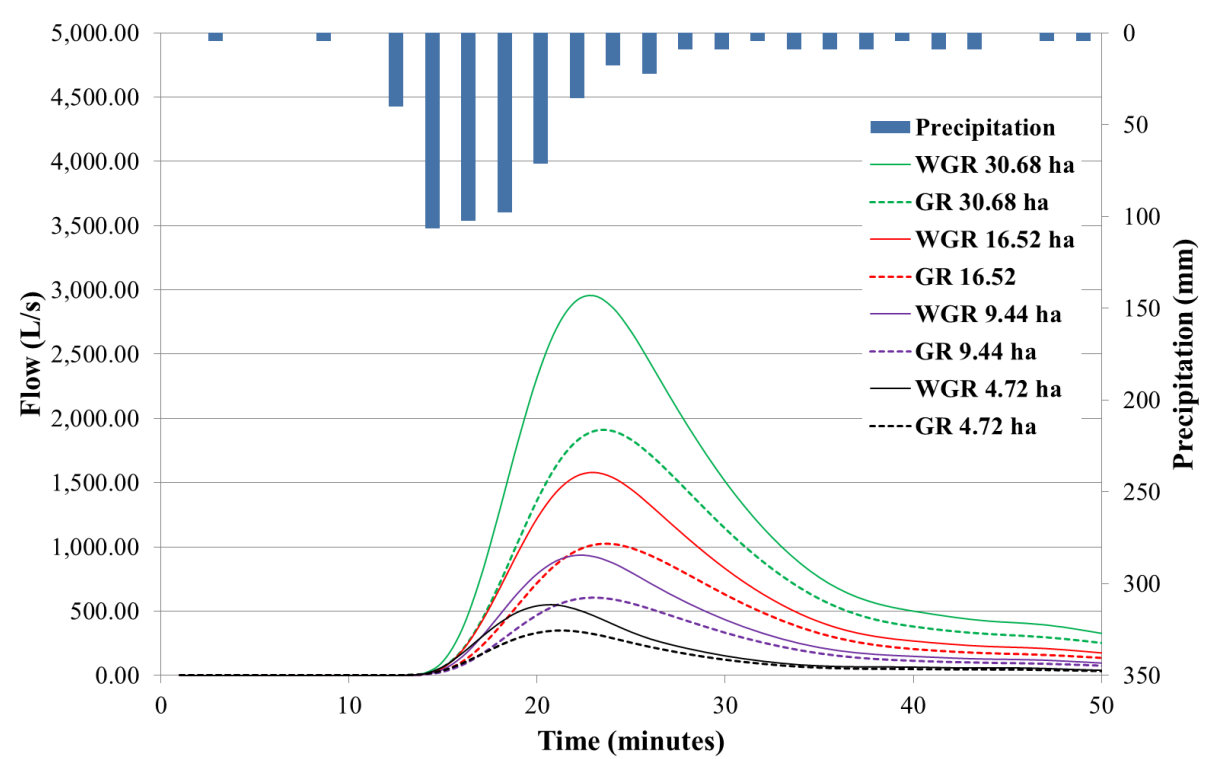

Figure 3. Hydrographs in drainage areas with 4.72, 9.44, 16.52 and 30.68 ha for rainfall event 2 (WGR: without green roof; GR: with green roof).

runoff in such structures. The great advantage of using this methodology is that it is easily adapted to similar GRs and its widespread use in Brazil.

\subsection{GR widespread implementation effect at different scales}

Seven rainfall events ( 6 observed +1 design) were selected to elucidate the MEGR impact on stormwater control (volume and peak flow) at different drainage area. The results of the reduction of volume runoff $\left(V_{\mathrm{R}}\right)$ and peak flow $\left(Q_{R}\right)$ are presented for eight cross sections with drainage areas ranging from 0.03 (one lot) to 30.68 ha (27 600 lots) (Table 3). Also, in Figs. 2 and 3 are presented the hydrographs for two of the selected rainfall events.

According to the results (Table 3), the MEGR allowed to reduce peak flows along the basin, although this effect is less pronounced as the basin area increases. This reduction is a consequence of impervious surfaces as streets and sidewalks, whose runoff is not affected by MEGR control. The MEGR's effect on the $V_{R}$ showed constant from the source 
Table 3. Volume reduction $\left(V_{\mathrm{R}}\right)$ and peak flows $\left(Q_{R}\right)$ in each drainage area for the seven events $(\%)$.

\begin{tabular}{|c|c|c|c|c|c|c|c|c|c|c|c|c|c|c|}
\hline \multirow[t]{2}{*}{$\begin{array}{r}\text { Area } \\
\text { (ha) }\end{array}$} & \multicolumn{2}{|c|}{ Rainfall 1} & \multicolumn{2}{|c|}{ Rainfall 2} & \multicolumn{2}{|c|}{ Rainfall 3} & \multicolumn{2}{|c|}{ Rainfall 4} & \multicolumn{2}{|c|}{ Rainfall 5} & \multicolumn{2}{|c|}{ Rainfall 6} & \multicolumn{2}{|c|}{$\begin{array}{l}\text { Design } \\
\text { Rainfall }\end{array}$} \\
\hline & $V_{\mathrm{R}}$ & $Q_{R}$ & $V_{\mathrm{R}}$ & $Q_{R}$ & $V_{\mathrm{R}}$ & $Q_{R}$ & $V_{\mathrm{R}}$ & $Q_{R}$ & $V_{\mathrm{R}}$ & $Q_{R}$ & $V_{\mathrm{R}}$ & $Q_{R}$ & $V_{\mathrm{R}}$ & $Q_{R}$ \\
\hline 0.03 & 55.54 & 60.31 & 44.04 & 56.16 & 52.64 & 61.32 & 50.43 & 56.91 & 54.93 & 59.32 & 45.58 & 56.03 & 35.25 & 47.04 \\
\hline 0.79 & 36.80 & 42.26 & 29.17 & 37.19 & 34.93 & 41.18 & 33.46 & 38.95 & 36.39 & 40.15 & 30.22 & 39.33 & 24.10 & 31.82 \\
\hline 1.57 & 36.79 & 41.20 & 29.17 & 37.25 & 34.92 & 40.69 & 33.46 & 38.51 & 36.38 & 38.96 & 30.22 & 39.76 & 24.10 & 30.38 \\
\hline 2.36 & 36.79 & 41.24 & 29.17 & 37.25 & 34.92 & 40.72 & 33.46 & 38.53 & 36.38 & 38.94 & 30.22 & 39.75 & 24.10 & 30.42 \\
\hline 4.72 & 36.79 & 40.95 & 29.17 & 36.26 & 34.92 & 39.39 & 33.46 & 38.15 & 36.38 & 38.72 & 30.21 & 39.13 & 24.10 & 30.18 \\
\hline 9.44 & 36.79 & 39.58 & 29.17 & 35.31 & 34.92 & 38.77 & 33.46 & 37.34 & 36.38 & 38.63 & 30.21 & 38.24 & 24.10 & 28.94 \\
\hline 16.52 & 36.79 & 39.90 & 29.17 & 35.32 & 34.92 & 38.59 & 33.46 & 37.45 & 36.38 & 38.78 & 30.21 & 38.34 & 24.10 & 28.47 \\
\hline 30.68 & 36.79 & 40.07 & 29.17 & 35.53 & 34.92 & 38.49 & 33.46 & 37.68 & 36.38 & 38.69 & 30.21 & 38.58 & 24.10 & 28.76 \\
\hline
\end{tabular}

Rainfall no.: Volume (mm). Duration (min.). Max. Intensity ( $\mathrm{mm} \mathrm{h}^{-1}$ ) - Rainfall 1: 6.69, 40, 35.68; Rainfall 2: 19.41, 50, 106.67; Rainfall 3: 9.84, 38, 69.49; Rainfall 4: 12.20, 40, 59.22; Rainfall 5: 6.80, 36, 38.76; Rainfall 6: 7.95, 24, 58.50; Design Rainfall: $38.63,60,120.63$ (design rainfall with a return period of 5 years).

analysis due to the limitation of water retention only at this scale. However, the runoff control due to MEGR use is significant when compared with a basin with impervious roof even for large scales analysis.

On average, $V_{\mathrm{R}}$ and $Q_{R}$ were higher as closer to the source $\left(V_{\mathrm{R}}=48 \%\right.$ and $\left.Q_{R}=57 \%\right)$, and smaller for large scale $\left(V_{\mathrm{R}}=32 \%\right.$ and $\left.Q_{R}=38 \%\right)$. The higher $V_{\mathrm{R}}$ and $Q_{R}$ occurred in events of low rainfall volume (rainfall event 1 and 5), which was already expected, due to the reduction in the capacity of water retention in the MEGR as the rainfall volume increases (Table 3). Close to the source there is a correlation of $81 \%(84 \%)$ between total rainfall volume and $V_{\mathrm{R}}\left(Q_{R}\right)$; for an area of $0.79 \mathrm{ha}$, this correlation is of $78 \%$ (92\%); and above this scale, this correlation does not change considerably due to the small variation of the $V_{\mathrm{R}}$ and $Q_{R}$, as previously discussed.

It is important to note, that even if results are based on measured individual GR results, and all outcomes are sound with available literature, there are no measures of basin-scale results GR implementation, and some uncertainties may be included in modeling.

\section{Conclusions}

This research validated a tool for the assessment of structural management measures (specifically GR) to address changes in flood characteristics in the city's water management planning. The monitoring showed that GR introduces a mean reduction of $45 \%$ of runoff volume at each event indicating that the MEGR would be almost equivalent to the maintenance of a pervious surface. This data also permitted the calibration of a basin scale detailed model that showed that the effect in the reduction of volumes and peak flows when traditional buildings roofs are substituted by green roofs. With the model was stablished that GR efficiency increases as rainfall volume and intensity decreases and the efficiency decreases as the basin size increases. In any case, the GR proved to be an excellent technology to be considered in the city's water management planning.
Acknowledgements. The authors would like to acknowledge CAPES for its financial support provided through a fellowship awarded to the first author.

\section{References}

Beyer, P. O.: Technical Report: measuring the thermal performance of Ecoroof, Steam and Refrigeration Laboratory, Department of Mechanical Engineering, Federal University of Rio Grande do Sul, Rio Grande do Sul, 2007.

Carter, T. L. and Rasmussen, T. C.: Hydrologic behavior of vegetated roofs, J. Am. Water Resour. Assoc., 42, 1261-1274, 2006.

Clark, S. E., Baker, K. H., Mikula, J. B., Burkhardt, C. S., and Lalor, M. M.: Infiltration vs. surface water discharge: Guidance for stormwater managers, Project Number 03-SW-4, Water Environment Research Foundation, USA, 220 pp., 2006.

Getter, K. L., Rowe, D. B., and Andresen, J. A.: Quantifying the effect of slope on extensive green roof stormwater retention, Ecol. Eng., 31, 225-231, 2007.

Gibbs, J., Luckett, K., Jost, V., Morgan, S., Yan, T., and Retzlaff, W.: Evaluating Performance of a Green Roof System with Different Growing Mediums, Sedum Species and Fertilizer Treatments, in: Proceedings of the Illinois State Academy of Science Annual Meeting, Chicago, USA, 2006.

Goff, K. M. and Gentry, R. W.: The Influence of Watershed and Development Characteristics on the Cumulative Impacts of Stormwater Detention Ponds, Water Resour. Manage., 20, 829860, 2006.

James, W. P., Bell, J. F., and Leslie, D. L.: Size and Location of Detention Storage, J. Water Resour. Pl. Manage., 113, 15-28, 1987.

Kim, K.: The application of the biosphere reserve concept to urban areas: the case of green rooftops for habitat network in Seoul, in: Annals of the New York Academy of Sciences, New York, USA, 187-214, 2004.

Miller, C., Weeks, K., Bass, B., Berghage, R., and Berg, S.: Stormwater Policy as a Green Roof (Dis) Incentive for Retail Developers, in: Proceedings of Cities Alive: 8th Annual Green Roof \& Wall Conference, Vancouver, Canada, 2010.

Nagase, A. and Dunnett, N.: Amount of water runoff from different vegetation types on extensive green roofs: Effects of plant 
species, diversity and plant structure, Landsc. Urban Plan., 104, 356-363, 2012.

NRCS - Natural Resources Conservation Service: US Department of Agriculture (USDA), Urban hydrology for small watersheds, Technical Release 55 (TR-55), 2nd Edn., Natural Resources Conservation Service, Conservation Engineering Division, USA, 1986.

NRCS - Natural Resources Conservation Service: US Department of Agriculture (USDA), Part 630 - Hydrology - National Engineering Handbook, Chapter 16 - Hydrographs, Natural Resources Conservation Service, Conservation Engineering Division, USA, 2007.

Park, A. and Cameron, J. L.: The influence of canopy traits on throughfall and stemflow in five tropical trees growing in a Panamanian plantation, Forest Ecol. Manage., 255, 1915-1925, 2008.

Renterghem, T. V. and Botteldooren, D.: Reducing the acoustical façade load from road traffic with green roofs, Build. Environ., 44, 1081-1087, 2009.

Rosenzweig, C., Gaffi, S., and Parshall, L.: Green Roofs in the New York Metropolitan Region: Research Report, Columbia University Center for Climate Systems Research and NASA Goddard Institute for Space Studies, USA, 2006.
Schaake, J. C.: Modeling Urban Runoff as a Deterministic Process, in: Treatise Urban Water Systems, Proceedings, Institute on Urban Water Systems, Fort Collins, Colorado State University, USA, 343-401, 1971.

Tassi, R.: Effect of micro-reservoirs for on-site detention over a macrodrainage network system, MSc dissertation in Water Resources and Sanitation, Federal University of Rio Grande do Sul, Porto Alegre, Brazil, 155 pp., 2002.

Tassi, R. and Villanueva, A. O. N.: Analysis of the impact of microreservoirs in the costs of an urban drainage system, Brazil. J. Water Resour., 9, 89-98, 2004.

Vecchia, F.: Light Green Coverage (LGC): experimental test, in: Proceedings of the 6th National Meeting of Comfort in the Built Environment, Maceió, Brazil, 2005.

Yang, J., Yu, Q., and Gong, P.: Quantifying air pollution removal by green roofs in Chicago, Atmos. Environ., 42, 7266-7273, 2008. 